Guidelines

\title{
National Consensus in the Use of the Flash Glucose Monitoring System in Portugal
}

\author{
Helena Cardoso ${ }^{\text {* }}$, Davide Carvalho ${ }^{\mathrm{b}}$, Estevão Pape ${ }^{\mathrm{c}}$, Francisco Carrilho ${ }^{\mathrm{d}}$, João Filipe \\ Raposo $^{\mathrm{e}}$, Miguel Melof ${ }^{\mathrm{f}}$ Ema Carvalho ${ }^{\mathrm{g}}$, Rui Duarte ${ }^{\mathrm{h}}$
}

\begin{abstract}
${ }^{a}$ Guest Associate Professor of the Medical School of Porto University, Director of the Endocrinology, Diabetes and Metabolism Service, Porto Hospital and University Centre, Porto, Portugal.

${ }^{b}$ President of the Portuguese Society of Endocrinology, Diabetes and Metabolism, Associate Professor, Faculty of Medicina, Universidade do Porto, I3S Core Investigator, Director of Department of Endocrinology, Diabetes and Metabolism, Centro Hospitalar Universitário de S. João, Porto, Portugal. Coordinator of the Diabetes Mellitus Centre of Studies of the Portuguese Society of Internal Medicine, Service Director - Garcia da Orta Hospital, Internist and Diabetologist at Garcia da Orta Hospital, Almada, Portugal.

${ }^{d}$ Former Director of the Endocrinology, Diabetes and Metabolism Service, Coimbra University and Hospital Centre, Coimbra, Portugal.

'Vice-President of the Portuguese Society of Diabetology, Guest Assistant Professor of Public Health of the Medical Sciences Faculty of the Universidade

Nova de Lisboa, Clinical Director of the Portuguese Diabetes Association (APDP), Lisbon, Portugal.

${ }^{f}$ Vice-President of the Portuguese Society of Endocrinology, Diabetes and Metabolism, Guest Assistant Professor of the Medical School of Coimbra University,

Endocrinologist at the Endocrinology, Diabetes and Metabolism Service, Coimbra University and Hospital Centre, Coimbra, Portugal.

${ }^{h}$ Nurse, Day Hospital of the Endocrinology, Diabetes and Metabolism Service, at the São João Hospital and University Centre, Porto, Portugal.

iPresident of the Portuguese Society of Diabetology, Internist and Diabetologist of the Portuguese Diabetes Association (APDP), Lisbon, Portugal.
\end{abstract}

\section{INFORMAÇÃO SOBRE O ARTIGO}

Historial do artigo:

Received/ Recebido: 2019-06-03

Accepted/Aceite: 2019-07-05

Online: 2019-09-30

\section{Keywords:}

Blood Glucose Self-Monitoring/methods;

Consensus;

Diabetes Mellitus, Type 1/blood;

Portugal;

Wearable Electronic Devices.

\section{Palavras-chave:}

Automonitorização da Glicemia/métodos;

Consenso;

Diabetes Mellitus Tipo 1/sangue;

Dispositivos Electrónicos Usáveis;

Portugal.

\section{A B S T R A C T}

Monitoring of glucose levels is essential in the management of diabetes, particularly in insulin ther-

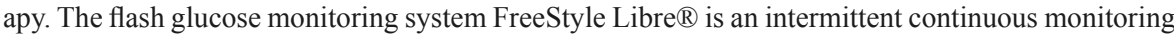
system that adds a set of new data to the traditional blood glucose determinations and that, when properly used, can lead to better glucose control through more personalized and rigorous clinical advice, as well as greater involvement and responsibility of the patients in the management of their condition. The recommendations outlined here aim to guide and standardize clinical practice and communication with the patient, namely: 1) New parameters for glucose assessment 2) Reading and interpretation of the ambulatory glucose profile (AGP) and 3) Interpretation of trend arrows and therapeutic adjustments.

\section{Consenso Nacional para a Utilização do Sistema de Monitorização Flash da Glicose em Portugal}

\section{R E S U M O}

A monitorização dos níveis de glicose é essencial na gestão da diabetes, em particular em regimes te-

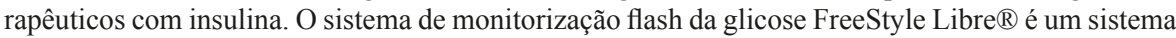
de monitorização contínua intermitente, que acrescenta um conjunto de novos dados às tradicionais determinações de glicose capilar e que, quando adequadamente utilizado, poderá conduzir a um melhor controlo da glicemia através de um aconselhamento clínico mais personalizado e rigoroso e de um maior envolvimento e responsabilização dos doentes. As recomendações aqui delineadas têm como objetivo orientar e uniformizar a prática clínica e a comunicação com o doente, nomeadamente no que diz respeito a: 1) Novos parâmetros de avaliação da glicose 2) Leitura e interpretação do perfil ambulatório de glicose (AGP) e 3) Interpretação das setas de tendência e ajustes terapêuticos.

\footnotetext{
* Autor Correspondente / Corresponding Author.

E-Mail: helenacardoso@icbas.up.pt (Maria Helena Cardoso)

Serviço de Endocrinologia, Diabetes e Metabolismo, Hospital de Santo António - Centro Hospitalar do Porto.

Largo Professor Abel Salazar, 4099-001 Porto

Portugal

https://doi.org/10.26497/na190022

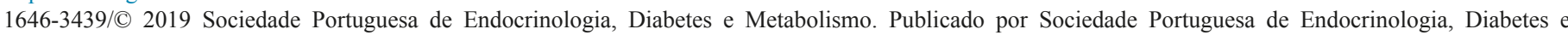
Metabolismo. Este é um artigo Open Access sob uma licença CC BY-NC-ND (http://creativecommons.org/licenses/by-nc-nd/4.0/).
} 


\section{Introduction}

Diabetes mellitus (DM) is a chronic disease characterised by the presence of hyperglycaemia, which in turn leads to the development of macro- and microvascular complications. The treatment of DM includes different options - pharmaceutical and nonpharmaceutical - that aim to normalise blood glucose levels with the goal of not only preventing long-term vascular complications, but also to avoid the acute problems of day-to-day hyperglycaemia or hypoglycaemia. One approach to management, namely insulin therapy, requires knowledge of daily blood sugar levels to ensure that correct doses of insulin are administered. In the last 50 years, technologies have been introduced that allow us to easily assess blood-sugar levels and make appropriate adjustments to therapy. ${ }^{1}$

Landmark clinical trials, including the United Kingdom Prospective Diabetes Study (UKPDS), Diabetes Control and Complications (DCCT) Trial and Epidemiology of Diabetes Intervention and Complications (EDIC) Trial, have shown that elevated glycated haemoglobin $(\mathrm{HbAlc})$ levels are predictive for the risk of future complications..$^{2-4}$ However, since $\mathrm{HbA} 1 \mathrm{c}$ reflects the average plasma glucose concentration over the previous 3 months, it cannot supply any information on day-to-day glycaemic stability, the variability of blood glucose over time, the risk, number and severity of episodes of hypoglycaemia, or the existence of periods of postprandial hyperglycaemia. Self-monitoring of blood glucose (SMBG) can, if done regularly, provide part of this information; however, many people with diabetes find SMBG to be inconvenient and painful and do not monitor their levels regularly. Additionally, the information collected regarding control, glycaemic stability and the number and frequency of episodes of hypoglycaemia is often incomplete. In this context, tools that allow for the monitoring of glucose in the interstitial fluid - continuous glucose monitoring (CGM) - are invaluable for people with diabetes, both in terms of glucose control as well as comfort and quality of life.

The introduction of the FreeStyle Libre flash glucose monitoring system (Abbott Diabetes Care Ltd), and its subsequent reimbursement by the National Health Service in Portugal, provides another option for interstitial glucose monitoring. Extending the use of this new technology will build on the knowledge gained from traditional SMBG readings, especially with regard to variation in glucose profiles, as well as creating benefits for glucose control based on the increased functionality of the device, such as trend arrows.

This publication summarises the recommendations of a panel of Portuguese experts on the use of the FreeStyle Libre system, and is intended to contribute to the standardisation of clinical practice and communication with the patient. The panel included members of three different societies (the Portuguese Society of Diabetology [SPD], the Portuguese Society of Endocrinology, Diabetes and Metabolism [SPEDM] and the Portuguese Society of Internal Medicine [SPMI]) and consisted of seven doctors and one diabetes specialist nurse, who as a patient with type 1 diabetes mellitus (T1DM) provided the patients perspective. The panel convened during the first semester of 2018 to review the literature and discuss and formulate recommendations for the use of the FreeStyle Libre flash glucose monitoring system with particular focus on: 1) the parameters used in the monitoring of glucose levels; 2) reading and interpretation of the ambulatory glucose profile (AGP); 3) use of trend arrows for guiding therapeutic adjustments.

\section{The FreeStyle Libre Flash Glucose Monitoring System}

The FreeStyle Libre flash glucose monitoring system is an intermittent continuous glucose monitoring system that can be used as a substitute for SMBG in the self-management of DM; it is indicated for measuring glucose levels in the interstitial fluid of people with DM aged over 4 years, including pregnant women. A sensor the size and shape of a small coin is applied to the posterior arm, which allows a small filament to measure interstitial glucose in the subcutaneous tissue. Each sensor remains active for a period of up to 14 days. A reader is used to scan the sensor to obtain instant information about current glucose levels, as well as the history of glucose readings over the previous eight hours. The reader also displays a trend arrow which indicates the direction and predicted rate of change in short-term glucose levels. ${ }^{5}$

The FreeStyle Libre system comes factory calibrated and does not require manual calibration with finger sticks to measure interstitial glucose levels. The AGP report generated by the FreeStyle Libre software complies with the recently published international consensus where it is recommended as a standard for visualisation of CGM to aid the clinical decision-making process for individuals with T1DM and Type 2 DM (T2DM). ${ }^{6}$ The AGP can be used both by health professionals and by people with diabetes or their carer to allow interpretation of results and facilitate dialogue and treatment review.

The IMPACT clinical trial in individuals with T1DM demonstrated a significant reduction of $38 \%(p<0.0001)$ in the mean time in hypoglycaemia $(<70 \mathrm{mg} / \mathrm{dL})$ in participants who used the FreeStyle Libre system in comparison with those who used SMBG. $^{7}$ This reduction was almost immediate, indicating a speedy adoption of the system, and was achieved without compromising HbA1c values. The participants who used the FreeStyle Libre system spent more time in the recommended target glucose range (70-180 mg/dL) than those who used SMBG [15.8 (2.9) vs 14.6 (2.9)] hours, $p=0.0006]$. The improvements observed - with respect to both hypoglycaemia and the time spent in the target range - were sustained throughout the six months of the trial. A subgroup analysis of individuals according to treatment modality, CSII or MDI, revealed similar results, confirming the clinical benefit of this system in both groups of individuals. ${ }^{8}$ Patients monitored their glucose levels using the flash glucose monitoring system more frequently compared to SMBG users (15.1 readings/ day vs 5.6 checks/day). Patient satisfaction was also significantly higher in those using the flash system, compared to those using SMBG (adjusted between-group difference -0.24 [SE: 0.049]; $p<$ $0.0001)$. No severe adverse events relating to the device were reported.

The results of the IMPACT trial were consistent with those observed in the REPLACE trial, which involved people with T2DM on MDI. A significant reduction of $43 \%$ of time spent in hypoglycaemia $(<70 \mathrm{mg} / \mathrm{dL})$ was observed in users of FreeStyle Libre compared to the SMBG control group ( $p=0.0006$ ), a reduction that was achieved without a concomitant increase in $\mathrm{HbA}_{1}$ levels. ${ }^{9}$ Access to their glycaemic profiles enabled users of the FreeStyle Libre system to achieve rapid improvements, which were maintained during a six-month extension of the trial. After 12 months, the time spent in hypoglycaemia $(<70 \mathrm{mg} / \mathrm{dL})$ was reduced by $50 \%(p=0.0002)$, with no reported device-related severe adverse events. ${ }^{10}$

These results were confirmed, in a real-world context, using data collected from more than 50000 users of the FreeStyle Libre device. Individuals were shown to scan their device an average of 16.3 times a day, and that higher rates of scanning were significantly associated with lower levels of estimated HbAlc, less time spent in hypoglycaemia/hyperglycaemia and more time spent in the target glucose range. ${ }^{11}$ It should be emphasised this 
data showed that estimated $\mathrm{HbA} 1 \mathrm{c}$ gradually decreases from $8.0 \%$ to $6.7 \%$ as the frequency of glucose readings increases from the lowest to the most frequent scanning groups (from 4.4 to 48.1 readings/day respectively; $p<0.001) .11$ These results were subsequently confirmed by a wider analysis, which included over 237000 users and more than 1.5 million sensors. ${ }^{12,13}$ Favourable results have also been demonstrated for use in pregnant women ${ }^{14}$ and paediatric patients. ${ }^{15}$

\section{Monitoring of Glucose Levels: Beyond HbA1c to New Parameters}

HbA1c levels are the established reference marker in the assessment of glycaemic control of DM. However, it is difficult to tailor this single measurement to the needs of each individual and additional parameters should be included to better reflect the dynamic nature of glycaemia. These include: the time spent in the target range; average glucose levels; the definition of and time spent in hypoglycaemia and hyperglycaemia; and various indices of glycaemic variability. This variability in glucose levels has been shown to increase reactive oxygen species and endothelial dysfunction, which are key components in the pathogenesis of diabetes complications. ${ }^{16}$ Clinical studies have shown that this variability is associated with increases in the risk of micro- and macrovascular complications in individuals with T1DM and T2DM, to a greater extent than general exposure to glucose. ${ }^{17-19}$ However, although the importance of glycaemic variability is well established in the literature, the same cannot be said of the definition of the parameters used to measure it. In fact, glycaemic variability is a complex measurement, characterised by a certain amplitude, duration and frequency. In a consensus published in December 2017, specialists recommended that glycaemic variability be preferably assessed by the coefficient of variation $(\mathrm{CV})$ or standard deviation (SD) of mean glucose levels, and that it should be taken into account in the general glycaemic profile chart. A CV of $36 \%$ or above is associated with unstable glucose levels. ${ }^{6}$

\section{Panel Recommendations}

With regard to the parameters used in the monitoring of glucose, the panel formulated the following recommendations:

- According to publications by the American Association of Clinical Endocrinologists (AACE), the American College of Endocrinology (ACE), and the Advanced Technologies \& Treatments for Diabetes (ATTD), a glucose evaluation report should provide the following data: average glucose levels, estimated HbAlc levels, proportion of time spent in different glucose concentration ranges, exposure to hypoglycaemia (time and number of episodes of minimum duration of 15 minutes), CV and/or SD. ${ }^{6,20}$

Recently eA1c is being replaced by the new term glucose management indicator (GMI) to reflect the fact that it is a measure derived from glucose values and can provide an indication of the current state of a person's glucose management but not always match closely a corresponding laboratory measured A1C..$^{38}$

The limits of the target ranges of glucose concentration should be adjustable according to the needs of each patient; one option would be to define hyperglycaemia as values above $180 \mathrm{mg} / \mathrm{dL}$, hypoglycaemia as levels below $70 \mathrm{mg} /$ $\mathrm{dL}$, clinically significant hypoglycaemia as levels below 54 $\mathrm{mg} / \mathrm{dL}$, and the recommended target range as $70-180 \mathrm{mg} / \mathrm{dL}$.

- Glycaemic variability is a complementary parameter to HbA1c levels in the monitoring of people with diabetes.
- The software associated with CGM systems, such as the FreeStyle Libre system, should provide a direct measurement of glycaemic variability that is easily interpretable by patients and health professionals.

Reading and Interpretation of the Ambulatory Glucose Profile

The standardisation of the approach to monitoring glucose levels is critical in the management of people with diabetes and may result in a better level of control for each individual. The introduction of CGM systems has further emphasised this need, as the information provided by these systems can be complex and hard to interpret. Mazze et al and the International Diabetes Center have developed an approach called the ambulatory glucose profile (AGP) which, in a visually clear and statistically detailed way, shows exposure to glucose, its variability, and the time in the target range, based on the data collected through SMBG or CGM over a specific period of time. ${ }^{21,22}$ International consensus recommendations have called for the use of the AGP as a standard report for analysing glucose data. ${ }^{6}$

An AGP report consists of three different parts: a summary of the descriptive statistics (which includes glucose exposure and variability, percentage of values in the target range as well as percentage of values below/far below and above/far above target, and the average number of readings per day during the period of data analysis); a graphic visualisation of a 'standard-day', in which all the collected data for a defined period is condensed and presented as if it had occurred in a single period of 24 hours. The AGP is constituted by a median line and by the curves corresponding to the $25^{\text {th }}-75^{\text {th }}$ percentiles, also termed the interquartile range (IQR) and the $10^{\text {th }}-90^{\text {th }}$ percentiles, also termed the interdecile range (IDR); as well as a summary of the glucose variation in each 'standard day' (which allows verification of the variability from day to day). ${ }^{23,24}$ The graphic representation of readings across a standard day is of unquestionable value, as it allows for the identification of patterns in glucose variation and problem areas where intervention may be possible. The median line shows the usual exposure to glucose, while the amplitude of areas determined by the percentile curves indicates glucose variability: the width of the $25^{\text {th }}-75^{\text {th }}$ percentile band around the median line indicates the "usual" variability, while the width of the $10^{\text {th }}-90^{\text {th }}$ percentile band indicates "occasional" variability. ${ }^{25}$ Periods where the risk of hypoglycaemia is high or worse than usual correspond to the times when the $10^{\text {th }}$ percentile line approaches or surpasses the minimum glucose concentration limit considered to define these episodes (usually $70 \mathrm{mg} / \mathrm{dL}$ ).

In addition to the AGP report, the software associated with the Freestyle Libre system also has an additional information chart (Fig. 1). This divides the glucose variation in the AGP into four periods and indicates, for each of them: the probability of the patient entering hypoglycaemia; the proximity of the median to the therapeutic goal, and; the amplitude of the variability below the median. This indication is given through an intuitive colour code (green, yellow, red) and helps to identify trends and risk of hypoglycaemia and hyperglycaemia, as well as situations in which the administration of a corrective insulin bolus to address an elevated glucose may result in a higher risk of hypoglycaemia. ${ }^{26}$

The use of the AGP for analysing data may improve glycaemic control by providing information in a systematic and intuitive way that allows for the identification of daily patterns of hypoglycaemia and/or hyperglycaemia. It is an important tool that can support the clinical decision process and facilitate doctor-patient communica- 


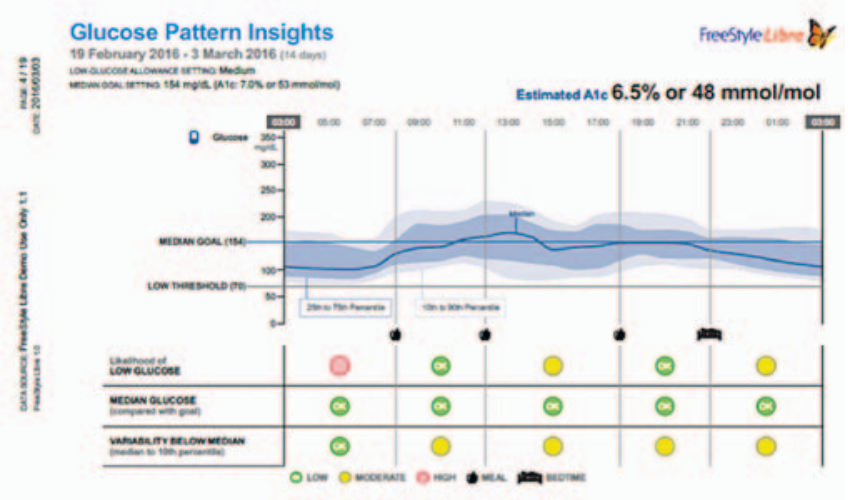

Figure 1. Example of an AGP as supplied by the Freestyle Libre device (Abbott), including the additional table that describes, for each period of the day, the probability of the individual incurring hypoglycaemia, the closeness of the median to the therapeutic goal, and the extent of the variability below the median [reproduced with permission].

tion, allowing the latter to visualise the effects of their behaviour and the therapeutic adherence to glucose control measures and, consequentially, a greater understanding of their diabetes treatment. International recognition of AGP has been accompanied by published recommendations which aim to guide the systematic analysis of AGP in the context of daily clinical practice. These recommendations usually take the form of an algorithm, which focuses essentially on three key steps: 1) analysing the quality of the collected data; 2) analysing the probability of hypoglycaemic periods; and 3) dividing the day into four parts for detailed analysis and discussion of each of them with the patient. ${ }^{6,25-27}$

\section{Panel Recommendations}

The panel agrees that the analysis of the AGP report should focus on the following points: 1) quality of the data; 2) the target glucose range; 3 ) episodes of hypoglycaemia; 4) glucose variability; 5) the median curve and identification of glucose patterns; and 6) overall analysis of the exposure to glucose. In addition, the panel made the following specific recommendations for some of the points listed, namely:

\section{- Analysis of the quality of the data}

- In agreement with other consensus statements, the panel recommends that 14 days' worth of data with $70 \%$ or more of sensor data captured should provide an adequate quantity of information to interpret an AGP report. It is possible to make informative readings with fewer days; however, it should be kept in mind that overlapping days with very distinct patterns may dilute certain glycaemic trends and impair their correct visualisation.

- The days analysed in an AGP report should reflect the typical therapeutic daily routine, holidays, days with different work schedules, or periods of transition between different insulin schemes may influence the profile and, if needed, should be evaluated separately to determine patterns associated to these specific periods.

- It is important to note that the data collected by the sensor in the first hours of use may have a greater associated error due to insertion-site factors.

- Determining the target range and associated time period

- The standard target range is $70-180 \mathrm{mg} / \mathrm{dL}$ (or 70-140 mg/dL for pregnant women); however, this range should be tailored to the needs of each individual. The AACE recommends that postprandial values can vary up to $140 \mathrm{mg} / \mathrm{dL}$, while the American Diabetes Association (ADA) accepts variations up to $180 \mathrm{mg} / \mathrm{dL}$. Thus, different values may be accepted according to the specific recommendations adopted.

- The time spent in the target range should be maximised, with a value above $70 \%$ being considered good; as with the target range limits, the objectives in terms of time spent in the target range may be adjusted to the requirements of each individual and other metrics such as mean glucose $<154 \mathrm{mg} / \mathrm{dL}$ or time in hypoglycaemia $<3 \%-5 \%$ can also be considered as primary objectives, more easily attainable.

- Analysis of hypoglycaemia episodes

- The analysis of episodes of hypoglycaemia is particularly important, given the impact that these episodes have on the patient's health and quality of life, and as such should be priority when analysing the AGP reports. The analysis of these episodes should keep in mind their frequency and severity.

- Patients should be advised to confirm CGM glucose with capillary blood glucose in case of hypoglycaemia and to take into account that the accuracy of CGM systems is reported to be lower in hypoglycaemic range, potentially overestimating hypoglycaemia.

\section{- Analysis of glucose variability}

- The analysis of glucose variability should keep in mind the lifestyle of the patient. It is known that poor adherence to medication or lifestyles with variable routines (for example, individuals who work in shifts) can widen the amplitude of the IQR and IDR and complicate the process of counselling. In cases of individuals with very wide glucose variability, analysis of the daily glucose variation graphs may provide additional insights.

- Analysis of the median curve and recognition of patterns

- The median curve should be carefully analysed to identify patterns (for example, glucose spikes or characteristic curves between meals or in the nocturnal period); this information should be used for therapeutic reassessment and readjustment.

\section{Interpretation of Trend Arrows and Therapeutic Adjustments}

In general, adjustment of insulin doses is made after considering the following data: glucose levels, glucose target value, carbohydrate ingestion, and insulin calculation parameters (insulin/ carbohydrate ratio and sensitivity factor). Traditionally, the glucose values used to trigger dose adjustment are obtained from SMBG, thus corresponding to a unique one-off value. However, the development of CGM systems has allowed the contextualisation of that value through the information present in the glucose variation profile and the trend arrows. The latter indicates the direction and speed of the change in glucose levels, taking into account the data collected in the most-recent 15 to 30 minutes before a measurement. This information has the potential to change the paradigm of therapeutic insulin adjustment, which can stop being based on a static measurement with no additional context and start being based on a forecast of glucose levels. However, to date no randomised clinical trials have been performed to determine the best way to incorporate information from trend arrows. Data has shown that trend arrows allow us to predict with accuracy what will happen in the next four hours, which has the potential to support assessment of safe glucose levels associated with driving. ${ }^{28}$ The first postprandial hours and after insulin administration seem to be the moment where there may be less precision. ${ }^{29}$ The precision of the two different systems - Dexcom G5 and FreeStyle 
Libre - seem to be similar. ${ }^{30}$ The recommendations that existed until now, briefly discussed below, are essentially based on the experience of experts, of people with diabetes, and on the few available clinical studies. ${ }^{31-35}$

There are two types of recommendations for insulin dose adjustments based on trend arrows: the first recommendation is based on a percentage correction to the usual insulin doses, while the second takes into account the 'predicted' glucose value at the end of a set period of time. The first recommendation is derived from research by the Diabetes Research in Children Network (DirecNet): in this, the usual insulin dose should be increased at an increment of $10 \%$ or $20 \%$ when a fast or very fast (respectively) increase in glucose level is observed; conversely, a reduction of $10 \%$ or $20 \%$ should be applied to the inverse situation. ${ }^{31}$ The second recommendation, which adjusts the insulin according to the 'predicted' glucose level, is supported by evidence from several studies. ${ }^{32-35}$ These publications all recommend using an expected glucose level 30 to 45 minutes after the time of reading as the basis for the insulin adjustment. The difference between them is in the way that this value is used to define the insulin adjustment. Pettus and Edelman suggest that the predicted glucose level be directly incorporated into the calculation of the dose, using the usual correction factor. The other authors present a simplified approach in which, through the use of averages and taking into account different ranges of insulin sensitivity, a value in insulin units is obtained which should be added or subtracted to the usual dose, depending on the direction of the trend arrows. ${ }^{32-35}$

It is worth noting that, despite the lack of data supporting these recommendations, people with diabetes actively use the information that is provided to them by the trend arrows for adjusting the therapeutic doses of insulin. A survey conducted in 2013 - before the publication of all the recommendations except those of DirecNet - showed that the majority of individuals, regardless of the type of diabetes or form of insulin therapy (MDI or CSII), used the trend arrows to adjust the insulin dose. ${ }^{36,37}$ Interestingly, and though there were differences between individuals with T1DM or T2DM, in both

Table 1. Proposed therapeutic steps for users in response to glucose readings and trend arrows displayed on the FreeStyle Libre system (Abbott) when in a pre-prandial state (before insulin is administered).

PRE-PRANDIAL TREND ARROWS WITHOUT ACTIVE INSULIN

WHENEVER AN ARROW IS RISING OR FALLING, THE REASON FOR THE OBSERVED CHANGE SHOULD ALWAYS BE SOUGHT2,3

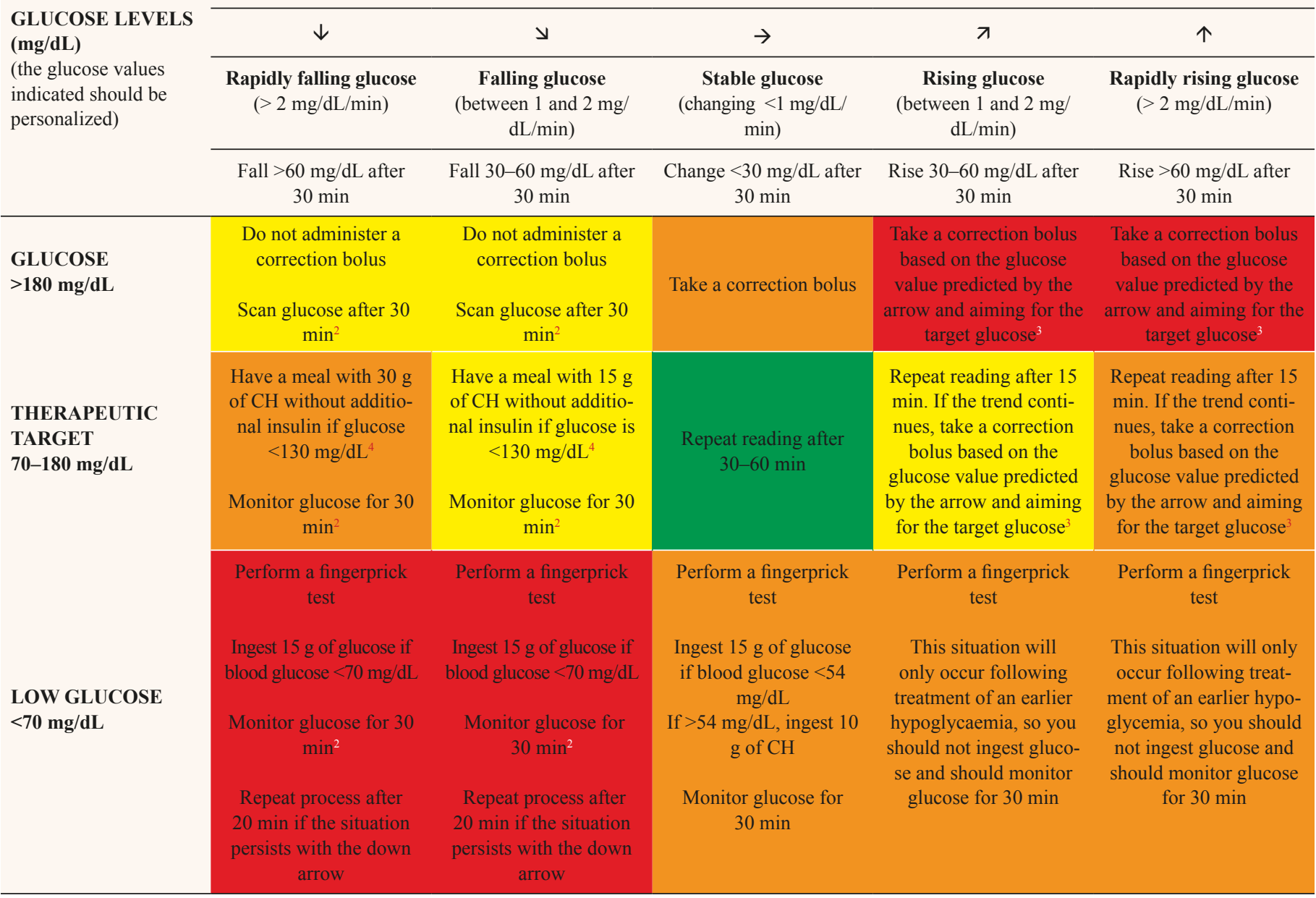

Risk in glycaemic control $++++++\quad 0$

$\mathrm{CH}$ - Carbohydrates

1. When a trend arrow is not horizontal, and glucose is above $70 \mathrm{mg} / \mathrm{dL}$, do not take action without repeating the reading twice with a 5 minutes interval. Adjust your approach according to the results.

2. Investigate the reason for the fall in glucose: Aerobic exercise? Is there still active insulin?

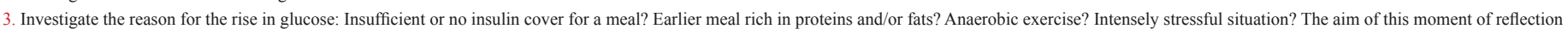
is to avoid repeating the situation.

4. If you are going to have a meal, subtract the 30 or $15 \mathrm{~g}$ of carbohydrates (depending on the case) in the calculation of mealtime insulin. 
Table 2. Proposed therapeutic steps for users in response to glucose readings and trend arrows displayed on the FreeStyle Libre system (Abbott) when in a postprandial state, following the administration of bolus insulin.

POST-PRANDIAL TREND ARROWS WITH ACTIVE INSULIN ${ }^{1}$

WHENEVER AN ARROW IS RISING OR FALLING, THE REASON FOR THE VARIATION SHOULD ALWAYS BE SOUGHT2,3

GLUCOSE LEVELS (mg/dL)

(the glucose values indicated should be

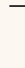
personalized)

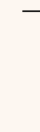

\section{Rapidly falling glucose \\ (>2 $\mathrm{mg} / \mathrm{dL} / \mathrm{min}$ )}

Fall $>60 \mathrm{mg} / \mathrm{dL}$ after
$30 \mathrm{~min}$

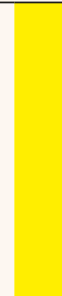

GLUCOSE

$>180 \mathrm{mg} / \mathrm{dL}$

\section{THERAPEUTIC \\ TARGET}

70-180 mg/dL

\section{LOW GLUCOSE $<70 \mathrm{mg} / \mathrm{dL}$}

\section{Scan again after $30 \mathrm{~min}^{2} \quad$ Scan again after $30 \mathrm{~min}^{2}$}

Have a meal with $30 \mathrm{~g}$
of $\mathrm{CH}$ without insulin if
glucose is $<130 \mathrm{mg} / \mathrm{dL}^{4}$
Monitor glucose for 30
$\min ^{2}$ Repeat the procedure if
necessary

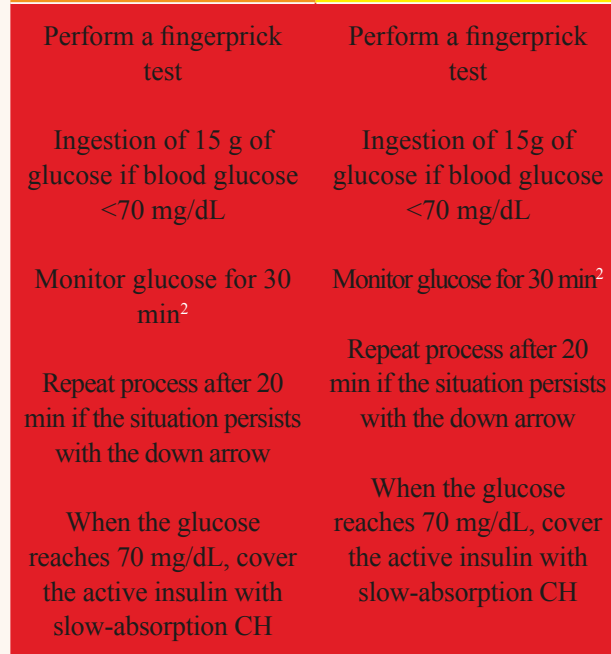

Have a meal with $15 \mathrm{~g}$ of $\mathrm{CH}$ without insulin if glucose is $<130 \mathrm{mg} / \mathrm{dL}^{4}$ Monitor glucose for 30 $\min ^{2}$

Repeat the procedure if necessary ${ }^{2}$ $\rightarrow$

Stable glucose

(changing $<1 \mathrm{mg} / \mathrm{dL} /$ $\min )$ $\pi$

Rising glucose
(between 1 and $2 \mathrm{mg} /$
$\mathrm{dL} / \mathrm{min}$ )

\section{$\uparrow$}

Rapidly rising glucose

$$
\text { (>2 mg/dL/min) }
$$

$\mathrm{dL} / \mathrm{min}$ )

Change $<30 \mathrm{mg} / \mathrm{dL}$ after

Rise $30-60 \mathrm{mg} / \mathrm{dL}$ after

Rise $>60 \mathrm{mg} / \mathrm{dL}$ after $<30 \mathrm{mg}$
$30 \mathrm{~min}$ $30 \mathrm{~min}$ $30 \mathrm{~min}$

Take a correction bolus if more than 2 hours have passed since the last insulin bolus, not including the active insulin

If less than 2 hours have passed, do not take a corrective bolus

Monitor glucose. If necessary, take a correction bolus when more than 2 hours have passed since the last insulin bolus

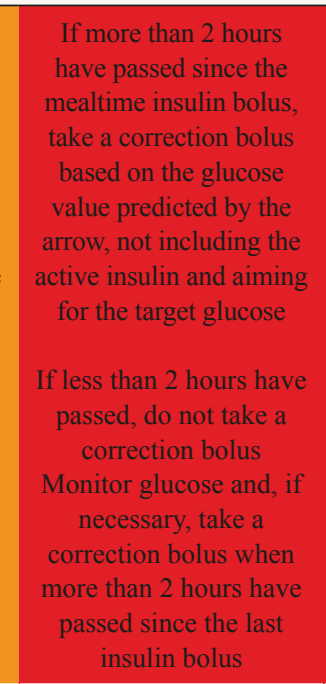

Repeat reading after 15 $\mathrm{min}$. If the trend persists and more than 2 hours have passed since the last insulin bolus, take a correction bolus based on the glucose value predicted by the arrow, not including the active insulin and aiming for the target glucose ${ }^{3}$

Perform a fingerprick test

Ingest $15 \mathrm{~g}$ of glucose if blood glucose $<54 \mathrm{mg}$ / dL. If $>54 \mathrm{mg} / \mathrm{dL}$, ingest $10 \mathrm{~g}$ of $\mathrm{CH}$

Monitor glucose for 30 $\min$

When the glucose reaches $70 \mathrm{mg} / \mathrm{dL}$, cover the active insulin with slow-absorption $\mathrm{CH}$ test

Do not take glucose

Monitor glucose for 60 min, with readings every $20 \mathrm{~min}$

Glucose is rising as a result of the approach taken, correction of hypoglycemia or dietary intake
Perform a fingerprick

\section{If more than 2 hours} have passed since the mealtime insulin bolus take a correction bolus based on the glucose value predicted by the arrow, not including the active insulin and aiming for the target glucose If less than 2 hours have passed, do not take a correction bolus Monitor glucose and, if necessary, take a correction bolus when more than 2 hours have passed since the last insulin bolus

Repeat reading after 15 $\mathrm{min}$. If the trend persists and more than 2 hours have passed since the last insulin bolus, take a correction bolus based on the glucose value predicted by the arrow, not including the active insulin and aiming for the target glucose ${ }^{3}$

Perform a fingerprick test

Do not take glucose

Monitor glucose for 60 min, with readings every $20 \mathrm{~min}$

Glucose is rising as a result of the approach taken, correction of hypoglycemia or dietary intake

1. When a trend arrow is not horizontal, and glucose is above $70 \mathrm{mg} / \mathrm{dL}$, do not take action without repeating the reading twice with a 5 minutes interval. Adjust your approach according to the results.

2. Investigate the reason for the fall in glucose: Aerobic exercise? Is there still active insulin?

3. Investigate the reason for the rise in glucose: Did you have a mealtime bolus? Did you adequately cover the CHs ingested? Did you take insulin 20 min before the meal? The aim of this moment of reflection is to avoid repeating the situation.

4. If you are going to have a meal, subtract the 30 or $15 \mathrm{~g}$ of carbohydrates (depending on the case) in the calculation of mealtime insulin. 
cases the adjustments used were greater than the conservative approach recommended in the DirecNet guidelines. ${ }^{36,37}$

\section{Panel Recommendations}

The panel considered that, given the absence of randomised clinical trials, there is no robust evidence that allows the formulation of a series of recommendations to be defined in this context.

Nonetheless, taking into account that: 1) because people with diabetes effectively use the information given by the trend arrows to adjust their insulin dose, there is a need for consensus on the matter in order to standardise clinical counselling; and 2), the trend arrows are an undeniable benefit of CGM systems that could, if properly used, improve the glycaemic control in people with diabetes; the panel has proposed a guide to therapeutic adjustment based on the interpretation of the trend arrows of the Freestyle Libre system and on the recommendations of Pettus and Edelman. ${ }^{32}$ It was decided that the level of glucose forecast 30 minutes after a reading (the average time for a rapid-acting insulin to start working) and applying the usual correction factor for each patient is a valid approach for using the trend arrows to calculate the correction bolus. It is important to stress that this proposal aims to generate initial guidelines. We recognise that these will be subject to alterations and revisions in line with the scientific evidence generated in the short and medium term by the ongoing accumulation of clinical data on this subject.

The panel also considered that: 1) the therapeutic adjustments will need to be tailored to the individual needs of each patient, their respective therapeutic target and the reason for adjustment (for example, the influence of meals and physical exercise); 2) therapeutic adjustment is a learning process for which clinical counselling is an important starting point: people wish to be and should be informed about the best way to manage their condition. It should be emphasised, however, that this is a continuous process, requires considerable education, and the results may not be immediate; 3 ) CGM enables verification of glucose levels following correction by repeat scanning, which is important to confirm if the effects are those expected and to reduce errors associated with any possible trend error inaccuracy; 4) taking into account the level of complexity of the calculations involved, patients should be informed that bolus calculators are essential tools to facilitate adjustment of the dose of insulin using the trend arrows and to avoid exposure to increase risk of hypoglycaemia by inappropriate correction of post prandial excursions; 5) patients should be warned of the danger of insulin stacking, so that any insulin still active in the body should be systematically subtracted from the new insulin bolus to be administered (for this purpose, and when properly scheduled, the computer programs available with insulin pumps and glucometers are a great help in calculating the most appropriate doses of insulin); and 6) trend arrow information becomes particularly relevant during lowglucose and evening periods to prevent hypoglycaemia.

Taking into account the above points, and in order to illustrate how the information obtained through the trend arrows should be incorporated into the therapy of the person with DM, Tables 1 and 2 give guidelines on the measures to be taken before the different combinations of glucose values/trend arrows in the pre- or postprandial periods (respectively).

\section{Conclusion}

The use of CGM systems, particularly the FreeStyle Libre flash glucose monitoring system, can lead to better glucose control in people with T1DM or T2DM who use insulin-based therapy, through more personalised and rigorous clinical advice, as well as greater involvement and responsibility in the management of their condition. These systems incorporate the use of new parameters for the evaluation of glucose control - namely the ability to analyse several days' worth of glucose data, the detection of patterns of variation in glucose, and the use of trend arrows for adjusting insulin doses - as a complement to HbAlc levels. However, any new tool entails a learning curve. These recommendations aim to standardise clinical practice and communication with the patient in order to maximise the available data. Finally, the panel highlighted: the importance of evaluating the variability of glucose; the need to adapt therapeutic objectives to the specifics of each patient (specifically in terms of the limits of the target range and the time spent in this range); the importance of hypoglycaemia episodes and of recognising the patterns in the analysis of AGP and subsequent therapeutic adjustments; and the recognition of the potential of trend arrows and the need for more studies to validate the approaches proposed.

\section{Acknowledgements:}

The writing of the manuscript had editorial support from W4Research through the medical writer Catarina L. Santos (PhD), which was sponsored by Abbott. Abbott did not influence the content of the publication.

\section{Responsabilidades Éticas}

Conflitos de Interesse: David Carvalho recebeu honorários de formador da Abbott e pertence ao Conselho Consultivo. Miguel Melo recebeu honorários de formador da Abbott. Os outros autores declaram a inexistência de conflitos de interesse na realização do presente trabalho.

Fontes de Financiamento: Não existiram fontes externas de financiamento para a realização deste artigo

Proveniência e Revisão por Pares: Não comissionado; revisão externa por pares.

\section{Ethical Disclosures}

Conflicts of interest: David Carvalho: Advisory Board and Fees for Abbott lectures, Fees for DEXCOM lectures. Miguel Melo: Fees for Abbott lecture. The other authors have no conflicts of interest to declare.

Financing Support: This work has not received any contribution, grant or scholarship.

Provenance and Peer Review: Not commissioned; externally peer reviewed.

\section{References}

1. Clarke SF, Foster JR. A history of blood glucose meters and their role in self-monitoring of diabetes mellitus. Br J Biomed Sci. 2012;69:83-93.

2. Stratton IM, Adler AI, Nei HAW, Matthews DR, Manley SE, Cull CA, et al. Association of glycaemia with macrovascular and microvascular complications of type 2 diabetes (UKPDS 35): prospective observational study. BMJ. 2000;321:405-12. doi:10.1136/bmj.321.7258.405.

3. Orchard TJ, Nathan DM, Zinman B, Cleary P, Brillon D, Backlund JC, et al. Association between seven years of intensive treatment of type 1 diabetes and long term mortality. JAMA. 2015;313:45-53. doi: 10.1001/ jama.2014.16107.

4. The Diabetes Control and Complications Trial Research Group. The effect of intensive treatment of diabetes on the development and progression of 
long-term complications in insulin-dependent diabetes mellitus. $\mathrm{N}$ Engl $\mathrm{J}$ Med. 1993;329:977-86.

5. Abbott. Freestyle Libre User Manual. Chicago: Abbot; 2016.

6. Danne T, Nimri R, Battelino T, Bergenstal RM, Close KL, DeVries JH, et al. International consensus on use of continuous glucose monitoring. Diabetes Care. 2017;40:1631-40. doi: 10.2337/dc17-1600.

7. Bolinder J, Antuna R, Geelhoed-Duijvestijn P, Kröger J, Weitgasser R. Novel glucose-sensing technology and hypoglycaemia in type 1 diabetes: a multicentre, non-masked, randomised controlled trial. Lancet. 2016;388:2254-63. doi: 10.1016/S0140-6736(16)31535-5.

8. Oskarsson P, Antuna R, Geelhoed-Duijvestijn P, Kröger J, Weitgasser $\mathrm{R}$, Bolinder J. Impact of flash glucose monitoring on hypoglycaemia in adults with type 1 diabetes managed with multiple daily injection therapy: a pre-specified subgroup analysis of the IMPACT randomised controlled trial. Diabetologia. 2018;61:539-50. doi: 10.1007/s00125-017-4527-5.

9. Haak T, Hanaire H, Ajjan R, Hermanns N, Riveline JP, Rayman G. Flash Glucose-sensing technology as a replacement for blood glucose monitoring for the management of insulin-treated type 2 diabetes: a multicenter, open-label randomized controlled trial. Diabetes Ther. 2017;8:55-73. doi: 10.1007/s13300-016-0223-6.

10. Haak T, Hanaire H, Ajjan R, Hermanns N, Riveline JP, Rayman G. Use of flash glucose-sensing technology for 12 months as a replacement for blood glucose monitoring in insulin-treated type 2 diabetes. Diabetes Ther. 2017;8:573-86. doi: 10.1007/s13300-017-0255-6.

11. Dunn TC, Xu Y, Hayter G, Ajjan RA. Real-world flash glucose monitoring patterns and associations between self-monitoring frequency and glycaemic measures: A European analysis of over 60 million glucose tests. Diabetes Res Clin Pract. 2018;137:37-46. doi: 10.1016/j. diabres.2017.12.015.

12. Pryor H, Budiman ES, Xu Y. Real-world patterns of daytime and nocturnal hypoglycemia during flash continuous glucose monitoring. diabetes. 2018;67(Suppl 1):70-LB

13. Jangam S, Xu Y, Hayter G, Dunn T. Glucose variability and flash glucose monitoring in the real world. Diabetes. 2018;67(Suppl 1):71-LB.

14. Scott EM, Bilous RW, Kautzky-Willer A. Accuracy, user acceptability, and safety evaluation for the FreeStyle Libre flash glucose monitoring system when used by pregnant women with diabetes. Diabetes Technol Ther. 2018;20:180-8. doi: 10.1089/dia.2017.0386.

15. Edge J, Acerini C, Campbell F, Hamilton-Shield J, Moudiotis C, Rahman $\mathrm{S}$, et al. An alternative sensor-based method for glucose monitoring in children and young people with diabetes. Arch Dis Child. 2017;102:5439. doi: 10.1136/archdischild-2016-311530.

16. Ceriello A, Ihnat MA. "Glycaemic variability": A new therapeutic challenge in diabetes and the critical care setting. Diabet Med. 2010;27:862-7. doi: 10.1111/j.1464-5491.2010.02967.x.

17. Gorst C, Kwok CS, Aslam S, Buchan I, Kontopantelis E, Myint PK, et al. Long-term glycemic variability and risk of adverse outcomes: A systematic review and meta-analysis. Diabetes Care. 2015;38:2354-69. doi: $10.2337 / \mathrm{dc} 15-1188$.

18. Smith-Palmer J, Brändle M, Trevisan R, Orsini Federici M, Liabat S, Valentine W. Assessment of the association between glycemic variability and diabetes-related complications in type 1 and type 2 diabetes. Diabetes Res Clin Pract. 2014;105:273-84. doi: 10.1016/j.diabres.2014.06.007.

19. Suh S, Kim JH. Glycemic variability: How do we measure it and why is it important? Diabetes Metab J. 2015;39:273-82. doi: 10.4093/ dmj.2015.39.4.273.

20. Fonseca V, Grunberger G. Standard glucose reporting: follow-up to the February 2016 AACE CGM consensus conference. Endocr Pract. 2017;23:629-32.

21. Mazze RS, Strock E, Wesley D, Borgman S, Morgan B, Bergenstal R, et al. Characterizing glucose exposure for individuals with normal glucose tolerance using continuous glucose monitoring and ambulatory glucose profile analysis. Diabetes Technol Ther. 2008;10:149-59. doi: abs/10.1089/dia.2007.0293.
22. Mazze RS, Lucido D, Langer O, Hartmann K, Rodbard D. Ambulatory glucose profile: representation of verified self-monitored blood glucose data. Diabetes Care. 1987;10:111-7.

23. Kruger DF. The Utility and Interpretation of Ambulatory Glucose Profiles. Clin Rev. 2016;26:S1-8.

24. Bergenstal RM, Ahmann AJ, Bailey T, Beck RW, Bissen J, Buckingham $\mathrm{B}$, et al. Recommendations for standardizing glucose reporting and analysis to optimize clinical decision making in diabetes: The ambulatory glucose profile. J Diabetes Sci Technol. 2013;7:562-78.

25. Evans M, Cranston I, Bailey CJ. Ambulatory glucose profile (AGP): utility in UK clinical practice. Br J Diabetes. 2017;17:26-33.

26. Hammond P. Interpreting the ambulatory glucose profile. Br J Diabetes Vasc Dis. 2016;16(Suppl 1):S10-5. doi: org/10.15277/bjd.2016.072.

27. Matthaei S, DeAlaiz RA, Bosi E, Evans M, Geelhoed-Duijvestijn N, Joubert $\mathrm{M}$. Consensus recommendations for the use of ambulatory glucose profile in clinical practice. Br J Diabetes Vasc Dis. 2014;14:153-7. A

28. Rayman G, Kröger J, Bolinder J. Could FreeStyle Libre TM sensor glucose data support decisions for safe driving? Diabet Med. 2018;35:491-4. doi: wiley.com/10.1111/dme.13515.

29. Freckmann G, Link M, Westhoff A, Kamecke U, Pleus S, Haug C. Prediction quality of glucose trend indicators in two continuous tissue glucose monitoring systems. Diabetes Technol Ther. 2018;20:550-6. doi: 10.1089/dia.2018.0112.

30. Freckmann G, Link M, Pleus S, Westhoff A, Kamecke U, Haug C. Measurement performance of two continuous tissue glucose monitoring systems intended for replacement of blood glucose monitoring. Diabetes Technol Ther. 2018;20:541-9. doi: 10.1089/dia.2018.0105.

31. Diabetes Research in Children Network (DirecNet) Study Group. Use of the DirecNet Applied Treatment Algorithm (DATA) for Diabetes Management with a Real-Time Continuous Glucose Monitor (the FreeStyle Navigator) Diabetes. Pediatr Diabetes. 2008;9:142-7.

32. Pettus J, Edelman S V. Recommendations for using real-time continuous glucose monitoring (rtCGM) data for insulin adjustments in type 1 diabetes. J Diabetes Sci Technol. 2017;11:138-47. doi: $10.1177 / 1932296816663747$.

33. Klonoff DC, Kerr D. A Simplified approach using rate of change arrows to adjust insulin with real-time continuous glucose monitoring. J Diabetes Sci Technol. 2017;11:1063-9. doi: 10.1177/1932296817723260.

34. Aleppo G, Laffel LM, Ahmann AJ, Hirsch IB, Kruger DF, Peters A, et al. A practical approach to using trend arrows on the Dexcom G5 CGM System for the management of adults with diabetes. J Endocr Soc. 2017;1:1445-60. doi: 10.1210/js.2017-00388.

35. Laffel LM, Aleppo G, Buckingham BA, Forlenza GP, Rasbach LE, Tsalikian E, et al. A Practical Approach to Using Trend Arrows on the Dexcom G5 CGM System to Manage Children and Adolescents With Diabetes. J Endocr Soc. 2017;1:1461-76. doi: 10.1210/js.2017-00389.

36. Pettus J, Edelman SV. Differences in use of glucose rate of change (ROC) arrows to adjust insulin therapy among individuals with type 1 and type 2 diabetes who use continuous glucose monitoring (CGM). J Diabetes Sci Technol. 2016;10:1087-93. doi: 10.1177/1932296816639069.

37. Pettus J, Edelman S V. Use of glucose rate of change arrows to adjust insulin therapy among individuals with type 1 diabetes who use continuous glucose monitoring. Diabetes Technol Ther. 2016;18(S2):S234-42. doi:10.1089/dia.2015.0369.

38. Bergenstal RM, Beck RW, Close KL, Grunberger G, Sacks DB, Kowalski A,et al. Glucose Management Indicator (GMI): A New Term for Estimating A1C From Continuous Glucose Monitoring. Diabetes Care. 2018; 41: 2275-80. 